\title{
A Delphi Consensus Document on the Use of Single-Inhaler Fixed-Dose Triple Therapies in COPD Patients
}

This article was published in the following Dove Press journal: International Journal of Chronic Obstructive Pulmonary Disease

José Luis López-Campos ${ }^{1,2}$ Bernardino Alcázar Navarrete (iD ${ }^{3}$ Juan Antonio Riesco Miranda (D) 2,4 Borja G Cosío ${ }^{2,5}$

Juan P de-Torres ${ }^{6}$

Bartolomé Celli $^{7}$

Carlos A Jiménez-Ruiz ${ }^{8}$

Ciro Casanova Macario 9

'Unidad Médico-Quirúrgica de Enfermedades Respiratorias, Instituto de Biomedicina de Sevilla (IBiS), Hospital Universitario Virgen del Rocío/

Universidad de Sevilla, Sevilla, Spain; ${ }^{2}$ CIBER de Enfermedades Respiratorias (CIBERES), Instituto de Salud Carlos III, Madrid, Spain; ${ }^{3}$ Hospital de Loja, Loja, Granada, Spain; ${ }^{4}$ Hospital Universitario de Cáceres, Cáceres, Spain; ${ }^{5}$ Hospital Universitario Son Espases-IdISBa, Palma de Mallorca, Spain; ${ }^{6}$ Respirology Division, Queen's University, Kingston, ON,

Canada; ${ }^{7}$ Brigham and Women's Hospital, Harvard Medical School Boston, Boston, MA, USA; ${ }^{8}$ Unidad Especializada en Tabaquismo, Hospital Clínico San Carlos,

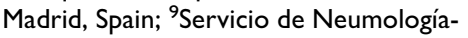
Unidad de Investigación, Hospital

Universitario La Candelaria, Universidad de La Laguna, La Laguna, Spain
Correspondence: José Luis López-Campos Hospital Universitario Virgen del Rocio, Avda. Manuel Siurot, S/N, Sevilla 4I0I3, Spain

Tel +349550I3I66

Email lcampos@separ.es
Introduction: Despite the evidence provided by clinical trials, there are some uncertainties and controversies regarding the use of triple inhaled therapy. With the aim of evaluating clinical practice in specialized respiratory units, a Delphi consensus document was implemented on the use of single-inhaler fixed-dose triple therapies after 1 year of use in Spain.

Methods: A scientific committee of COPD experts defined a thematic index, guided a systematic literature review and helped design the Delphi questionnaire. This was sent to the other 45 COPD experts between April and June 2019. Agreement/disagreement on 58 statements was tested in two rounds using a Likert scale. Replies were classified as a consensus when $\geq 80 \%$ of the panelists agreed; a majority when a degree of agreement of $\geq 66 \%$ was reached; and divergence if agreement was $<66 \%$.

Results: After two rounds, $44.44 \%$ of the statements reached consensus, $14.81 \%$ reached majority and $40.74 \%$ were divergent. Panelists agreed that escalating from double bronchodilation should be phenotype-based and aim to prevent exacerbations but not for improving symptoms. The addition of an antimuscarinic to inhaled corticosteroids combinations achieves improvement in lung function, symptoms and exacerbation prevention. Main safety concerns included the increased risk of pneumonia as compared to bronchodilator therapies, with similar cardiovascular effects. There was no consensus agreement on patient type response based on blood eosinophil counts or obstruction severity.

Conclusion: The low degree of consensus among panelists may reflect the complexity of severe COPD management. The information provided here may be useful to clinicians implementing personalized medicine for COPD patients.

Keywords: chronic obstructive pulmonary disease, LABA/LAMA, LABA/ICS, bronchodilator agents, inhaled corticosteroids, triple therapy, statements, Delphi consensus

\section{Introduction}

Chronic obstructive pulmonary disease (COPD) pharmacological treatments aim to reduce symptoms, reduce the frequency and severity of exacerbations. ${ }^{1,2}$ The current inhaled pharmacologic treatments for COPD comprise long-acting bronchodilators (LABD), including long-acting $\beta 2$ adrenergic (LABA) and long-acting muscarinic antagonists (LAMA), and inhaled corticosteroids (ICS). The combinations of these drugs have demonstrated clinical benefits for patients. Therefore, different single-inhaler fixed-dose combinations (FDC) are available. For more severe patients, triple therapy combinations, consisting of the addition of a LABA, a LAMA and an ICS, have been 
proposed in current recommendation documents. ${ }^{1,2}$ This combination may be given in multiple inhalers; or as FDC, in a single inhaler. ${ }^{3}$

Single-inhaler FDC triple therapy has been available since September 2018 and to date, several clinical trials have shown that it is beneficial compared with monotherapy and double therapies improving efficacy regarding lowering exacerbations and hospitalization rate. ${ }^{4,5}$ Clinical benefits have also been reported when using FDC triple therapy compared to tiotropium. ${ }^{6}$ In addition to the scientific evidence, in recent months it is beginning to gain clinical experience in its use since its commercialization. According to the current recommendation guidelines, triple therapy can be used in high risk patients with not very well-controlled exacerbations with two drugs and in severe cases of asthmaCOPD overlap ${ }^{1}$ as well as in patients who develop further exacerbations or with persistent breathlessness or exercise limitation on LABA/ICS therapy. ${ }^{2}$

Despite the results reported in the clinical trials, there is still disagreement and confusion among the scientific community on its practical use, mainly due to the uncertainty in situations not addressed in clinical trials. In this context, this Delphi consensus document provides information regarding the practical use of FDC triple therapy in specialized respiratory units for COPD patients. The document takes into account the available evidence and the experts' opinion after 1 year of use in Spain, while attempting to facilitate the decisions for clinical practice.

\section{Methods}

\section{Governance}

This is a document that uses a Delphi methodology comprising two rounds. A scientific committee was constituted, composed by a coordinator and six members with renowned expertise in COPD. The scientific committee was responsible for decision-making and, based on the results of the systematic review, created the Delphi questionnaire and modified it before the second round.

Fifty-one experts, who were not members of the scientific committee, were invited to participate as panelists in the Delphi questionnaire, based on their competence in the management of COPD and conforming the expert panel. The scientific committee prepared the list of participants by reviewing the list of Spanish pulmonologists who participate in the SEPAR national congress as chairs in COPD sessions, on the editorial board of the Spanish journal Archivos de Bronconeumologia with COPD articles and by the publications of Spanish members in PubMed related to COPD. Later this list was refined looking for national representativeness by regions. In order to validate the experience of the experts in COPD, all participants were required to answer three questions regarding their clinical and research expertise in COPD: 1) Is COPD your main area of interest?; 2) How long (years) is your experience in COPD patients management?; 3) How many COPD patients approximately do you visit monthly? No approval was required by any ethics committee, since it is a study based on a Delphi process gathering expert opinions without patient participation.

\section{Questionnaire Design}

In order to establish the relevant areas regarding the use of triple therapy in patients with stable COPD to be covered with the document, a thematic index (annex) was defined by the scientific committee in a kick-off virtual meeting, held on September 20, 2018. Based on the thematic index, a non-exhaustive systematic review of the literature was performed through Pubmed and an evidence document was generated to synthesize the results from the selected studies. Based on the thematic index and with the help of the evidence document, the scientific committee proposed statements to be included in the Delphi questionnaire, which were agreed and validated through a teleconference based on the scientific committee criteria. The validated questionnaire consisted of 48 statements divided into 10 sections covering the efficacy of FDC triple therapy vs other therapies (efficacy of FDC triple therapy vs LABA/ LAMA, efficacy of FDC triple therapy vs LABA/ICS, efficacy of FDC triple therapy vs open triple therapy), safety of FDC triple therapy vs other therapies (general safety of FDC triple therapy, safety of FDC triple therapy vs LABA/LAMA; safety of FDC triple therapy vs LABA/ ICS; safety of FDC triple therapy vs open triple therapy); treatment with FDC triple therapy; devices; and costs. The responses regarding the degree of agreement were given using a Likert scale (degrees 1-5, where 1 means completely disagree and 5 completely agree).

\section{Consensus Process}

The consensus process was carried out using a Delphi method comprising two rounds. ${ }^{7}$ The Delphi technique is a reliable prospective process that permits us to obtain the experts' perception in a specific field and expresses the agreement level reached among them, through their anonymous answers. In round 1, members of the expert panel 
were asked to express their degree of agreement with the 48 statements and their answers were analyzed using the following criteria: Agreement (sum of 4 and 5 Likert scale values); neither agreement nor disagreement (NAND; value 3 in Likert scale); disagreement (sum of 1 and 2 values). According to this, the scientific committee defined consensus when $\geq 80 \%$ of the panelists coincided with the same agreement category; majority when $\geq 66 \%$ of them coincided and divergence when $<66 \%$ of the panellists coincided with the same agreement category. For round 2 of the Delphi process, the statements which reached consensus in the first round were not included. For this round, each answer in divergence or majority was analyzed, in order to decide if they should be more specific or reformulated. Following this, some statements were reformulated to improve understandability and increase the agreement percentage in the second round.

\section{Results}

Forty-five panelists completed both round 1, comprising 48 statements, and round 2 (45 statements) of the Delphi questionnaire. Eighteen items were modified before the second round in order to improve clarity. The 45 members included in the final panel were distributed homogeneously over 16 provinces in Spain. In reply to the questions regarding their expertise, most of the participants replied COPD was their main area of interest (42 out of 45) and had more than 10 years of experience managing COPD (41 out of 45). Regarding the patients visited per month, 14 panelists visited more than 100 patients per month, whereas 23 of them visited between 51 and 100 and 8 of them visited less than 50 patients per month.

The distribution of agreements in the two rounds is shown in Figure 1. Altogether, after the two rounds, the panelists had provided their degree of agreement with 54 statements (the ones that reached consensus in round 1 plus all the statements of round 2). Of these, 24 items (44.44\%) reached consensus, whereas 8 items (14.81\%) reached majority agreement and discrepancy was reached in 22 items $(40.74 \%)$.

\section{Efficacy of FDC Triple Therapy vs Other Therapies}

The statements regarding FDC triple therapies vs LABA/ LAMA are shown in Table 1, section a. Out of the 12 statements, three of them achieved consensus, one of these being consensus in disagreement, and two of them majority, whereas the panel showed divergence in seven of them. Two new questions ( $5 b$ and $9 b$ ) were added in round 2 with clarification purposes, and statement 6 was replaced by two new more specific statements (6a and $6 \mathrm{~b}$ ). The main consensus messages were an agreement for items 3 and 7, and a disagreement for item 4 .

For the group of statements which sought to compare FDC triple therapy vs LABA/ICS, 7 out of 10 statements achieved consensus, two of them majority and discrepancy was reached in three of them. It should be noted that two new statements were added to the second round in order to clarify the statements of the round 1. Also, question 15 was replaced with two new statements that were consulted

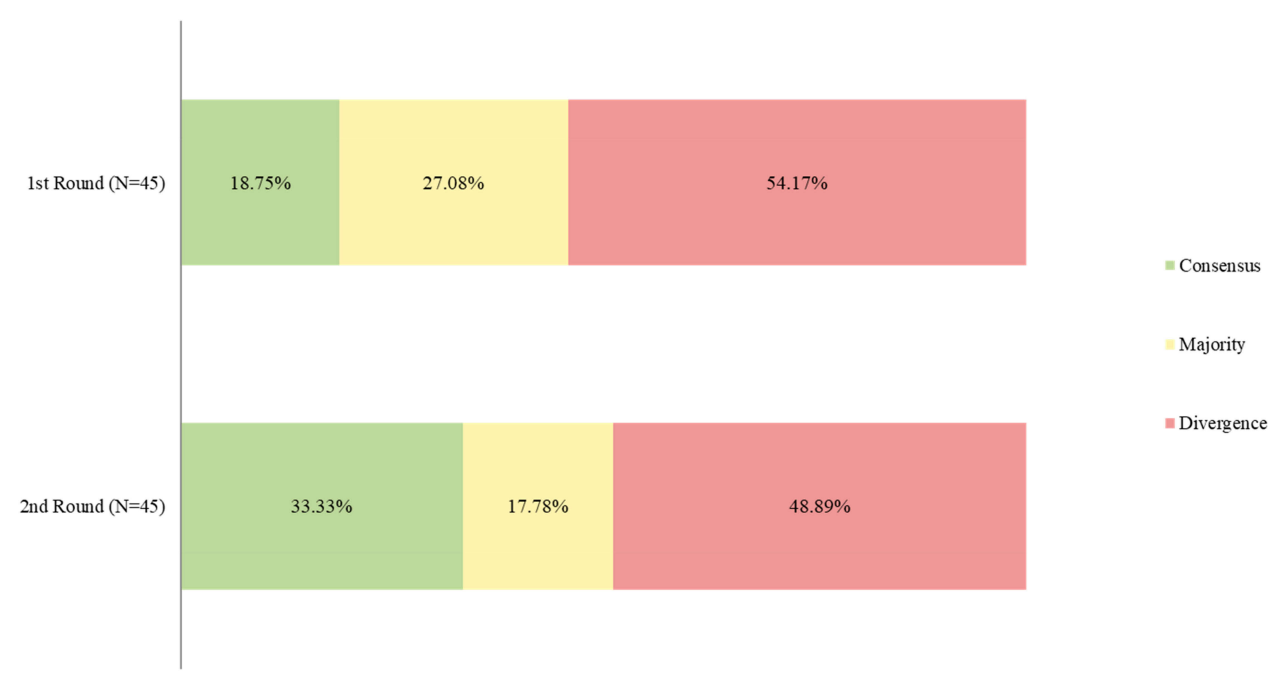

Figure I Results of the degree of agreement among the panelists after the Ist and 2 nd Delphi rounds. (N) number of panelists that participated in the Delphi round. 
Table I Results of the Degree of Agreement Among the Panelists with the Statements Regarding Efficacy of Single-Inhaler Fixed Triple Therapy vs LABA/LAMA, LABA/ICS and Open Triple Therapy After the two Delphi Rounds

\begin{tabular}{|c|c|c|c|c|}
\hline \# & Statement & $\begin{array}{l}\% \\
\text { Agreement }\end{array}$ & Round* & $\begin{array}{l}\text { Final } \\
\text { Results }\end{array}$ \\
\hline \multicolumn{5}{|c|}{ a. Efficacy of single-inhaler fixed triple therapy vs double therapy LABA/LAMA } \\
\hline I & $\begin{array}{l}\text { In a non-exacerbator COPD patient, with eosinophilia } \geq 300 \text {, single-inhaler fixed triple therapy is indicated before } \\
\text { dual LABA/LAMA. }\end{array}$ & $\begin{array}{l}55.56 \% \\
\text { Disagreement }\end{array}$ & 2 & Divergence \\
\hline 2 & $\begin{array}{l}\text { When deciding to use single-inhaler fixed triple therapy vs dual LABA/LAMA therapy, the COPD phenotype of the } \\
\text { patient is taken into account. }\end{array}$ & $\begin{array}{l}91.11 \% \\
\text { Agreement }\end{array}$ & 1 & Consensus \\
\hline 3 & $\begin{array}{l}\text { Single-inhaler fixed triple therapy is more effective than dual LABA/LAMA therapy to improve the pulmonary } \\
\text { function }\end{array}$ & $\begin{array}{l}44.44 \% \\
\text { Agreement }\end{array}$ & 2 & Divergence \\
\hline 4 & $\begin{array}{l}\text { Single-inhaler fixed triple therapy is more effective than dual LABA/LAMA therapy to improve dyspnea in } \\
\text { symptomatic patients }(C A T>10) \text {, independently of } F E V_{1} \text { and of the number of previous exacerbations. }\end{array}$ & $\begin{array}{l}80.00 \% \\
\text { Disagreement }\end{array}$ & 2 & Consensus \\
\hline $5 a$ & $\begin{array}{l}\text { Single-inhaler fixed triple therapy significantly improves the health-related quality of life (measured by the St. } \\
\text { George's Respiratory Questionnaire (SGRQ)) compared to dual LABA/LAMA therapy. }\end{array}$ & $\begin{array}{l}62.22 \% \\
\text { Agreement }\end{array}$ & 2 & Divergence \\
\hline $5 b$ & $\begin{array}{l}\text { In your clinical practice, the single-inhaler fixed triple therapy improves the health-related quality of life when } \\
\text { compared with dual LABA/LAMA therapy. }\end{array}$ & $\begin{array}{l}46.67 \% \\
\text { Agreement }\end{array}$ & 2 & Divergence \\
\hline 6a & $\begin{array}{l}\text { Single-inhaler fixed triple therapy is more effective than dual LABA/LAMA therapy to reduce the number of } \\
\text { exacerbations in a patient with COPD and } \mathrm{FEV}_{1}<50 \%\end{array}$ & $\begin{array}{l}62.22 \% \\
\text { Agreement }\end{array}$ & 2 & Divergence \\
\hline $6 b$ & $\begin{array}{l}\text { Single-inhaler fixed triple therapy is more effective than dual LABA/LAMA therapy to reduce the number of } \\
\text { exacerbations in a patient with COPD and frequent exacerbations. }\end{array}$ & $\begin{array}{l}77.78 \% \\
\text { Agreement }\end{array}$ & 2 & Majority \\
\hline 7 & $\begin{array}{l}\text { In COPD patients treated with dual LABA/LAMA therapy hospitalized because of one severe or two moderate } \\
\text { exacerbations, the treatment must be escalated to single-inhaler fixed triple therapy independently of the number } \\
\text { of eosinophils. }\end{array}$ & $\begin{array}{l}84.44 \% \\
\text { Agreement }\end{array}$ & 2 & Consensus \\
\hline 8 & $\begin{array}{l}\text { In COPD patients treated with dual LABA/LAMA therapy hospitalized because of one severe or two moderate } \\
\text { exacerbations and with a number of eosinophils }<100 \text {, the treatment must be escalated to single-inhaler fixed triple } \\
\text { therapy }\end{array}$ & $\begin{array}{l}51.11 \% \\
\text { Agreement }\end{array}$ & 2 & Divergence \\
\hline 9a & Single-inhaler fixed triple therapy improves COPD patients' survival compared to dual LABA/LAMA therapy & $\begin{array}{l}44.44 \% \\
\text { NAND }\end{array}$ & 2 & Divergence \\
\hline $9 b$ & $\begin{array}{l}\text { Single-inhaler fixed triple therapy improves survival of COPD patients with frequent exacerbations compared to } \\
\text { dual LABA/LAMA therapy }\end{array}$ & $\begin{array}{l}66.67 \% \\
\text { Agreement }\end{array}$ & 2 & Majority \\
\hline \multicolumn{5}{|c|}{ b. Efficacy of single-inhaler fixed triple therapy vs dual LABA/ICS therapy } \\
\hline 10 & $\begin{array}{l}\text { In a COPD patient receiving monotherapy LABA or LAMA it is correct to escalate to single-inhaler fixed triple } \\
\text { therapy skipping dual LABA/ICS therapy }\end{array}$ & $\begin{array}{l}62.22 \% \\
\text { Disagreement }\end{array}$ & 2 & Divergence \\
\hline 11 & Single-inhaler fixed triple therapy is more effective than dual LABA/ICS therapy to improve pulmonary function & $\begin{array}{l}84.44 \% \\
\text { Agreement }\end{array}$ & 1 & Consensus \\
\hline 12 & Single-inhaler fixed triple therapy is more effective than dual LABA/ICS therapy to improve the symptoms & $\begin{array}{l}95.56 \% \\
\text { Agreement }\end{array}$ & 2 & Consensus \\
\hline 13 & $\begin{array}{l}\text { Single-inhaler fixed triple therapy is more effective than dual LABA/ICS therapy to improve dyspnea in symptomatic } \\
\text { patients }(C A T>10) \text {, independently of FEV } \text { and of the number of previous exacerbations }\end{array}$ & $\begin{array}{l}95.56 \% \\
\text { Agreement }\end{array}$ & 2 & Consensus \\
\hline $14 a$ & $\begin{array}{l}\text { Single-inhaler fixed triple therapy significantly improves the health-related quality of life (measured by the SGRQ } \\
\text { questionnaire) compared with dual LABA/ICS therapy }\end{array}$ & $\begin{array}{l}95.56 \% \\
\text { Agreement }\end{array}$ & 2 & Consensus \\
\hline $14 b$ & $\begin{array}{l}\text { In your clinical practice, single-inhaler fixed triple therapy significantly improves health-related quality of life } \\
\text { compared to dual LABA/ICS therapy }\end{array}$ & $\begin{array}{l}75.56 \% \\
\text { Agreement }\end{array}$ & 2 & Majority \\
\hline $15 a$ & $\begin{array}{l}\text { Single-inhaler fixed triple therapy is more effective than dual LABA/ICS therapy reducing the number of } \\
\text { exacerbations in a COPD patient with } \mathrm{FEV},<50 \%\end{array}$ & $\begin{array}{l}84.44 \% \\
\text { Agreement }\end{array}$ & 2 & Consensus \\
\hline $15 b$ & $\begin{array}{l}\text { Single-inhaler fixed triple therapy is more effective than dual LABA/ICS therapy reducing the number of } \\
\text { exacerbations in a COPD patient with frequent exacerbations }\end{array}$ & $\begin{array}{l}93.33 \% \\
\text { Agreement }\end{array}$ & 2 & Consensus \\
\hline 16 & $\begin{array}{l}\text { In COPD patients treated with dual LABA/ICS therapy hospitalized because of one severe or two moderate } \\
\text { exacerbations, the treatment must be escalated to single-inhaler fixed triple therapy, independently of the number } \\
\text { of eosinophils }\end{array}$ & $\begin{array}{l}80.00 \% \\
\text { Agreement }\end{array}$ & 2 & Consensus \\
\hline 17 & $\begin{array}{l}\text { In COPD patients treated with dual LABA/ICS therapy hospitalized because of one severe or two moderated } \\
\text { exacerbations and with a number of eosinophils }<100 \text {, the treatment must be escalated to single-inhaler fixed } \\
\text { triple therapy }\end{array}$ & $\begin{array}{l}68.89 \% \\
\text { Agreement }\end{array}$ & 2 & Majority \\
\hline
\end{tabular}

(Continued) 
Table I (Continued).

\begin{tabular}{|c|c|c|c|c|}
\hline$\#$ & Statement & $\begin{array}{l}\% \\
\text { Agreement }\end{array}$ & Round* & $\begin{array}{l}\text { Final } \\
\text { Results }\end{array}$ \\
\hline $18 \mathrm{a}$ & $\begin{array}{l}\text { Single-inhaler fixed triple therapy improves survival in COPD patients compared to dual LABA/ICS therapy } \\
\text { Single-inhaler fixed triple therapy improves survival in COPD patients with frequent exacerbations compared to } \\
\text { dual LABA/ICS therapy }\end{array}$ & $\begin{array}{l}57.78 \% \\
\text { Agreement } \\
62.22 \% \\
\text { Agreement }\end{array}$ & 2 & $\begin{array}{l}\text { Divergence } \\
\text { Divergence }\end{array}$ \\
\hline \multicolumn{5}{|c|}{ c. Efficacy of single-inhaler fixed triple therapy } \\
\hline 19 & $\begin{array}{l}\text { Based on your clinical experience, currently efficacy differences exist among the known single-inhaler fixed triple } \\
\text { therapies }\end{array}$ & $\begin{array}{l}57.78 \% \\
\text { NAND }^{2}\end{array}$ & 2 & Divergence \\
\hline 20 & Single-inhaler fixed triple therapy is more effective than open triple therapy in improving the pulmonary function & $\begin{array}{l}46.67 \% \\
\text { NAND }^{2}\end{array}$ & 2 & Divergence \\
\hline 21 & Single-inhaler fixed triple therapy is more effective than open triple therapy in improving dyspnea & $\begin{array}{l}64.44 \% \\
\text { Agreement }^{2}\end{array}$ & 2 & Divergence \\
\hline 22 & Single-inhaler fixed triple therapy is more effective than open triple therapy in improving quality of life & $\begin{array}{l}62.22 \% \\
\text { Agreement }^{2}\end{array}$ & 2 & Divergence \\
\hline 23 & $\begin{array}{l}\text { Single-inhaler fixed triple therapy is more effective than open triple therapy in reducing the number of moderate } \\
\text { and severe exacerbations }\end{array}$ & $\begin{array}{l}42.22 \% \\
\text { Disagreement }{ }^{2}\end{array}$ & 2 & Divergence \\
\hline 24 & $\begin{array}{l}\text { In the subgroup of patients suffering }>1 \text { moderate-severe exacerbation in the } 12 \text { previous months, the single- } \\
\text { inhaler fixed triple therapy is more effective than open triple therapy in reducing the number of moderate-severe } \\
\text { exacerbations }\end{array}$ & $\begin{array}{l}44.44 \% \\
\text { Agreement }^{2}\end{array}$ & 2 & Divergence \\
\hline
\end{tabular}

Notes: The final results were determined considering the degree of agreement among the panellists meant consensus: $\geq 80 \%$; majority $\geq 66 \%$; or divergence (<66\%). NAND: neither agreement nor disagreement. *Indicates the round where the degree of agreement shown was reached. In bold those words changed from round one to round two.

in round 2 (Table 1, section b). Consensus on agreement was for items 11-14a, both 15 and 16 .

In reply to the six statements of the group which compared efficacy of fixed triple therapy vs open triple therapy, none of them achieved consensus or majority, being all divergent among the participants (Table 1, section c).

\section{Safety of FDC Triple Therapy vs Other Therapies}

The answers of the panelists to these statements are shown in Table 2. All items reached a consensus except for item 25 . The first question was formulated regarding the general safety of FDC triple therapy compared to others, and the replies given by the panelists were divergent. The question was reformulated in round 2, however, still divergence was found (Table 2, section a).

The second group of statements, about the safety of FDC triple therapy vs LABA/LAMA therapy comprised three statements, all achieving consensus by the panelists. Two of the consensuses reached were in disagreement with the statement, whereas only one was of agreement with it (Table 2, section b).

The two statements comparing the safety of FDC with the LABA/ICS therapy achieved consensus, one in agreement with the statement and the other one in disagreement
(Table 2, section c). Finally, all three statements about the safety of FDC triple therapy compared to open triple therapy also achieved consensus (two in agreement, one in disagreement) among the panelists (Table 2, section d).

\section{Treatment with FDC Triple Therapy in Specific Patient Types}

Of the five statements of this group of statements, three of them achieved majority, two of them majority in disagreement and one of them in agreement, whereas panelists had divergent replies in two of them (Table 3). The statements 35 , 36 and 37 were reformulated to improve understanding.

\section{Devices for FDC Triple Therapy}

Eight statements were consulted among the panelists, who achieved consensus in six of them, of which one was in disagreement, and discrepancy in two (Table 4).

\section{Costs Associated to FDC Triple Therapy vs Other Therapies}

This group included two statements, one of them achieving agreement in majority and the other one discrepancy among the panelists with neither agreement nor disagreement. The statement 48 was reformulated to increase specificity and avoid different interpretations (Table 5). 
Table 2 Results of the Degree of Agreement of the Panelists with the Statements Regarding Safety of Single-Inhaler Fixed Triple Therapy vs LABA/LAMA, LABA/ICS and Open Triple Therapy After the two Delphi Rounds

\begin{tabular}{|c|c|c|c|c|}
\hline \# & Statement & $\begin{array}{l}\% \\
\text { Agreement }\end{array}$ & Round* & $\begin{array}{l}\text { Final } \\
\text { Results }\end{array}$ \\
\hline \multicolumn{5}{|c|}{ a. General safety of single-inhaler fixed triple therapy } \\
\hline 25 & $\begin{array}{l}\text { Based on your clinical experience, currently differences exist in the safety profile of the different } \\
\text { known single-inhaler fixed triple therapies }\end{array}$ & $\begin{array}{l}62.22 \% \\
\text { Disagreement }\end{array}$ & 2 & Divergence \\
\hline \multicolumn{5}{|c|}{ b. Safety of single-inhaler fixed triple therapy vs dual LABA/LAMA therapy } \\
\hline 26 & $\begin{array}{l}\text { Single-inhaler fixed triple therapy has the same risk of producing pneumonia than dual LABA/ } \\
\text { LAMA therapy }\end{array}$ & $\begin{array}{l}86.67 \% \\
\text { Disagreement }\end{array}$ & 2 & Consensus \\
\hline 27 & $\begin{array}{l}\text { Single-inhaler fixed triple therapy produces similar cardiovascular adverse effects to those } \\
\text { produced by dual LABA/LAMA therapy }\end{array}$ & $\begin{array}{l}82.22 \% \\
\text { Agreement }^{\prime}\end{array}$ & I & Consensus \\
\hline 28 & $\begin{array}{l}\text { Single-inhaler fixed triple therapy produces similar local adverse effects to those produced by } \\
\text { dual LABA/LAMA therapy }\end{array}$ & $\begin{array}{l}82.22 \% \\
\text { Disagreement }\end{array}$ & 2 & Consensus \\
\hline \multicolumn{5}{|c|}{ c. Safety of single-inhaler fixed triple therapy vs dual LABA/ICS therapy } \\
\hline 29 & Single-inhaler fixed triple therapy causes more pneumonia cases than dual LABA/ICS therapy & $\begin{array}{l}80.00 \% \\
\text { Disagreement }\end{array}$ & I & Consensus \\
\hline 30 & $\begin{array}{l}\text { Single-inhaler fixed triple therapy produces similar cardiovascular adverse effects to those } \\
\text { produced by dual LABA/ICS therapy }\end{array}$ & $\begin{array}{l}88.89 \% \\
\text { Agreement }^{2}\end{array}$ & 2 & Consensus \\
\hline \multicolumn{5}{|c|}{ d. Single-inhaler fixed triple therapy vs open triple therapy } \\
\hline 31 & Single-inhaler fixed triple therapy causes more pneumonia cases than open triple therapy & $\begin{array}{l}86.67 \% \\
\text { Disagreement }\end{array}$ & 1 & Consensus \\
\hline 32 & $\begin{array}{l}\text { Single-inhaler fixed triple therapy produces similar cardiovascular adverse effects to those } \\
\text { produced by open triple therapy }\end{array}$ & $\begin{array}{l}82.22 \% \\
\text { Agreement }^{\prime}\end{array}$ & 1 & Consensus \\
\hline 33 & $\begin{array}{l}\text { Single-inhaler fixed triple therapy produces similar local adverse effects to those produced by } \\
\text { open triple therapy }\end{array}$ & $\begin{array}{l}84.44 \% \\
\text { Agreement }^{\prime}\end{array}$ & 1 & Consensus \\
\hline
\end{tabular}

Notes: The final results were determined considering the degree of agreement among the panelists: consensus $\geq 80 \%$; majority $\geq 66 \%$; or divergence (<66\%). NAND: neither agreement nor disagreement. *Indicates the round where the degree of agreement shown was reached. In bold are words changed from round one to round two.

\section{Discussion}

The present study provides the cumulative opinion of 45 experts on important statements regarding the use of FDC triple therapy vs other available treatments in the management of COPD patients. The experts' replies are based on their clinical practice and the scientific evidence. According to the results, the experts diverge on their perception of efficacy of FDC triple therapy vs LABA/LAMA, whereas their level of agreement is higher when compared to LABA/ ICS. Safety is perceived as similar among the different therapies. Regarding treatment with FDC triple therapy, the experts' views are generally aligned with the current recommendations, and they perceive cost-effectiveness in FDC triple therapy vs LABA/ICS but not vs LABA/LAMA.

The incorporation of new drugs and inhaler devices to the treatment paradigm of COPD constitutes a great opportunity to improve the management of COPD patients, and, although current guidelines provide general recommendations, there can be confusion and disagreement among healthcare providers in some aspects regarding the use of FDC triple therapy. ${ }^{8}$

Among the statements where the experts diverged most were around the efficacy of FDC triple therapy vs LABA/ LAMA in terms of quality of life and reduction of the number of exacerbations in patients with COPD and FEV1 $<50 \%$. This is probably because the scientific evidence available is not enough to establish a firm conclusion on this topic, $5,9,10$ which has been also shown in a recently published systematic review. ${ }^{11}$ The differences existing among the molecules, including the different results in lung function, symptoms or exacerbations, ${ }^{11}$ could also have influenced the replies since the molecules to be compared were not specified in the statements. Regarding the COPD patients with frequent exacerbations, the agreement, without reaching consensus, in the higher effectivity of FDC triple therapy vs LABA/ LAMA, is in agreement with the systematic reviews by Zheng et $\mathrm{al}^{10}$ and López-Campos et $\mathrm{al}^{11}$ that showed that 
Table 3 Results of the Degree of Agreement Among the Panelists with the Statements Regarding Treatment with Single-Inhaler Fixed Triple Therapy in Specific Patient Types After the two Delphi Rounds

\begin{tabular}{|c|c|c|c|c|}
\hline \# & Statement & $\begin{array}{l}\% \\
\text { Agreement }\end{array}$ & Round* & $\begin{array}{l}\text { Final } \\
\text { Results }\end{array}$ \\
\hline 34 & $\begin{array}{l}\text { In high risk, non-exacerbator COPD patients, with a number of eosinophils }>300 \text {, single-inhaler } \\
\text { fixed triple therapy is indicated as starting therapy }\end{array}$ & $\begin{array}{l}73.33 \% \\
\text { Disagreement }\end{array}$ & 2 & Majority \\
\hline 35 & $\begin{array}{l}\text { In patients with more than wo exacerbations and a number of eosinophils }<100 \text {, single-inhaler } \\
\text { fixed triple therapy is indicated as starting therapy }\end{array}$ & $\begin{array}{l}75.56 \% \\
\text { Disagreement }\end{array}$ & 2 & Majority \\
\hline 36 & $\begin{array}{l}\text { In patients with very severe obstruction }(\mathrm{FEV},<30 \%) \text { who do not present exacerbations, single- } \\
\text { inhaler fixed triple therapy is indicated as starting therapy }\end{array}$ & $\begin{array}{l}42.22 \% \\
\text { Disagreement }\end{array}$ & 2 & Divergence \\
\hline 37 & The use of single-inhaler fixed triple therapy needs to be indicated by the pneumologist & $\begin{array}{l}62.22 \% \\
\text { Disagreement }\end{array}$ & 2 & Divergence \\
\hline 38 & $\begin{array}{l}\text { To make the decision of using single-inhaler fixed triple therapy, it must be taken into account if } \\
\text { the patient has pneumonia precedent }\end{array}$ & $\begin{array}{l}75.56 \% \\
\text { Agreement }\end{array}$ & 2 & Majority \\
\hline
\end{tabular}

Notes: The final results were determined considering the degree of agreement among the panelists: consensus $\geq 80 \%$; majority $\geq 66 \%$; or divergence ( $<66 \%$ ). NAND: neither agreement nor disagreement. *Indicates the round where the degree of agreement shown was reached. In bold are those words changed from round one to round two.

Table 4 Results of the Degree of Agreement Among the Panelists with the Statements Regarding the Different Device Options After the two Delphi Rounds

\begin{tabular}{|c|c|c|c|c|}
\hline \# & Statement & $\begin{array}{l}\% \\
\text { Agreement }\end{array}$ & Round* & $\begin{array}{l}\text { Final } \\
\text { Results }\end{array}$ \\
\hline 39 & $\begin{array}{l}\text { The Ellipta }{ }^{\circledR} \text { device has shown a lesser number of critical errors compared to other devices that } \\
\text { use triple therapy }\end{array}$ & $\begin{array}{l}93.33 \% \\
\text { Agreement }^{2}\end{array}$ & 2 & Consensus \\
\hline 40 & $\begin{array}{l}\text { The fine particle with Modulite }{ }^{\circledR} \text { technique has shown bigger pulmonary deposit in peripheral } \\
\text { airways than other devices that use triple therapy }\end{array}$ & $\begin{array}{l}82.22 \% \\
\text { Agreement }^{2}\end{array}$ & 2 & Consensus \\
\hline 41 & $\begin{array}{l}\text { The pulmonary deposit originated by the single-inhaler fixed triple therapy is similar to the one } \\
\text { originated by the dual LAMA/LABA therapy }\end{array}$ & $\begin{array}{l}51.11 \% \\
\text { Agreement }^{2}\end{array}$ & 2 & Divergence \\
\hline 42 & $\begin{array}{l}\text { The pulmonary deposit originated by the single-inhaler fixed triple therapy is similar to the one } \\
\text { originated by the dual LABA/ICS therapy }\end{array}$ & $\begin{array}{l}60.00 \% \\
\text { Agreement }^{2}\end{array}$ & 2 & Divergence \\
\hline 43 & $\begin{array}{l}\text { Single-inhaler fixed triple therapy leads to a higher decrease in the number of critical errors than } \\
\text { open triple therapy }\end{array}$ & $\begin{array}{l}93.33 \% \\
\text { Agreement }^{\prime}\end{array}$ & I & Consensus \\
\hline 44 & $\begin{array}{l}\text { Single-inhaler fixed triple therapy leads to higher adherence to the treatment than open triple } \\
\text { therapy }\end{array}$ & $\begin{array}{l}93.33 \% \\
\text { Agreement }^{1}\end{array}$ & 1 & Consensus \\
\hline 45 & $\begin{array}{l}\text { The administration pattern of single-inhaler fixed triple therapy every } 12 \text { hours is more effective } \\
\text { than every } 24 \text { hours pattern }\end{array}$ & $\begin{array}{l}84.44 \% \\
\text { Disagreement }{ }^{2}\end{array}$ & 2 & Consensus \\
\hline 46 & $\begin{array}{l}\text { The administration pattern of single-inhaler fixed triple therapy every } 24 \text { hours improves the } \\
\text { adherence compared to every } 12 \text { hours pattern. }\end{array}$ & $\begin{array}{l}84.44 \% \\
\text { Agreement }^{2}\end{array}$ & 2 & Consensus \\
\hline
\end{tabular}

Notes: The final results were determined considering the degree of agreement among the panellists: consensus $\geq 80 \%$; majority $\geq 66 \%$; or divergence (<66\%). NAND: neither agreement nor disagreement. *Indicates the round where the degree of agreement shown was reached.

triple therapy significantly reduced moderate or strong exacerbations rate vs LABA/LAMA. Interestingly, and although the current guidelines do not support this statement, the consensus reached in the escalation from LABA/LAMA to FDC triple therapy independently of the number of eosinophils in patients hospitalized because of severe to moderate exacerbations, may have been based on the IMPACT study, ${ }^{4}$ where the annual rate of moderate or severe exacerbations was lower with triple therapy than with either doubletherapy combination, regardless of eosinophil level, ${ }^{4}$
Interestingly, the panelists may also have taken into account the results of the IMPACT study when reaching a majority consensus on the statement that FDC triple therapy improves survival of COPD patients with frequent exacerbations compared to LABA/LAMA therapy.

A higher degree of agreement was achieved among panelists on the efficacy of FDC triple therapy vs LABA/ ICS therapy, as evidenced from the FULFIL ${ }^{12}$ and TRILOGY trials. ${ }^{13}$ According to the results of IMPACT ${ }^{4}$ and FULFIL, ${ }^{12}$ the panelists also agreed on the higher 
Table 5 Results of the Degree of Agreement Among the Panelists with the Statements Regarding Costs of the Diverse Therapeutic Options for the COPD Patients After the two Delphi Rounds

\begin{tabular}{|l|l|l|l|l|}
\hline$\#$ & Statement & $\begin{array}{l}\% \\
\text { Agreement }\end{array}$ & $\begin{array}{l}\text { Round* } \\
\text { Final } \\
\text { Results }\end{array}$ \\
\hline 47 & $\begin{array}{l}\text { In patients with symptomatic COPD, the single-inhaler fixed triple therapy is more cost-effective } \\
\text { than the dual LABA/ICS therapy } \\
\text { In high-risk patients according to the GesEPOC definition, the single-inhaler fixed triple therapy is } \\
\text { more cost-effective than the dual LABA/LAMA therapy }\end{array}$ & $\begin{array}{l}75.56 \% \\
\text { Agreement } \\
5.33 \% \\
\text { NAND }\end{array}$ & 2 & Majority \\
Divergence
\end{tabular}

Notes: The final results were determined considering the degree of agreement among the panelists: consensus $\geq 80 \%$; majority $\geq 66 \%$; or divergence (<66\%). NAND: neither agreement nor disagreement. *Indicates the round where the degree of agreement shown was reached. In bold are those words changed from round one to round two.

efficacy of FDC triple therapy vs LABA/ICS in reducing exacerbations when the COPD patients have FEV1<50\% or frequent exacerbations. In the KRONOS study, however, no significant impact was reported. ${ }^{14}$ Regarding escalating from monotherapy to triple therapy, the panelists reply in accordance with the GOLD guides, ${ }^{2}$ agreeing that double therapy should precede triple. The disagreement regarding survival improvement may occur because only one of the combinations has shown improved survival and in previous studies similar survival rates amongst treatments has been found. $5,9,10,12,13$

Regarding FDC triple therapy vs open triple therapy, the divergence observed in all statements is due probably to the fact that some panelists based their opinion on their own clinical practice whereas the reference for others was the available scientific evidence from the literature, which shows no inferiority in the FEV1 and no significant differences in exacerbation rate, dyspnea and quality of life in fixed triple therapy compared to open triple therapy. ${ }^{6,15}$

In relation to safety, the opinion (although not consensus) of the panelists on the lack of difference among FDC triple therapies versus LABA/ICS is consistent with the clinical trials ${ }^{4,12,14}$ and Zheng et al, ${ }^{10}$ who observed that triple therapy was not associated with an increase in the risk of adverse events compared to LABA/ICS. Regarding differences with LABA/LAMA, several studies ${ }^{4,14}$ and the systematic review by Zheng et al, ${ }^{10}$ have shown the safety profile of FDC triple therapy is different than that of LABA/LAMA in pneumonia risk. These results may have supported the consensus of the panelists. In the TRIBUTE study, the pneumonia risk was reported to be similar in patients of each treatment arm. ${ }^{5} \mathrm{On}$ the other hand, the response of the panelists regarding the cardiovascular adverse effects produced by FDC triple therapy or LABA/LAMA is consistent with the results of the TRIBUTE and KRONOS studies. ${ }^{5,14}$ The panelists' response is also consistent with several studies and a systematic review when considering that adverse effects related to FDC triple therapy are similar to those of open triple therapy. ${ }^{6,10,15}$

The majority of panelists disagreed on whether to use FDC as the starting therapy in specific patients' profiles. This is in accordance with the current GOLD document, which recommends escalation to triple therapy in patients who continue to exacerbate or have persistent breathlessness or exercise limitation while on LABA/ICS. ${ }^{2}$ Also, the Spanish GesEPOC guidelines recommend using triple therapy in high-risk patients whose exacerbations are not controlled with $2 \mathrm{LABD}$ or a LABD/ICS combination. ${ }^{1}$

The experts reached consensus on the observation that the device Ellipta ${ }^{\circledR}$ has demonstrated less critical errors than other devices used for triple therapy and that the metered dose inhaler with Modulite ${ }^{\circledR}$ technique has demonstrated higher pulmonary deposit in peripheral airways than other devices used for triple therapy, which was highlighted as an advantage in a Spanish consensus. ${ }^{16}$ Instead, it is of interest that when the devices were not specified in the statement, the replies varied among the experts and consensus was not achieved. The same was observed when the experts were consulted on whether FDC triple therapy originates a pulmonary deposition pattern similar to that of LABA/LAMA and LABA/ICS. Similarly, the panelist agree that there are reductions of critical errors with FDC vs open triple therapy as is supported by studies ${ }^{17-19}$ that highlight the potential improvement in adherence when using fixed triple therapy. In this regard, it is remarkable that consensus was reached on the higher adherence of FDC triple therapy vs open triple therapy, despite the lack of clinical evidence. The higher adherence with 24-hours pattern compared to 12-hours pattern was also agreed by the panelists. Likewise, the results show that they perceive no differences in efficacy in these two dosing patterns, even though there is no data proving it.

Regarding the perception of higher cost-effectiveness of the FDC triple therapy versus dual LABA/ICS therapy, it is possibly due to the differences in efficacy and safety 
existing among both therapies, although little is known about it to date. This is in agreement with a post hoc analysis of the FULFIL study, where fixed triple therapy appeared to reduce the economic burden and the use of medical resources compared with $\mathrm{LABA} / \mathrm{ICS} .^{20}$ On the contrary, it is interesting that agreement was not achieved regarding the cost-effectiveness of FDC triple therapy compared to LABA/LAMA, probably due to the limited clinical and scientific evidence in this specific area.

Although there is growing evidence for a clinical benefit of triple therapy over monotherapy or LABA/ICS treatment, more results on real-world trials would be very beneficial, as well as the results of ongoing clinical trials comparing triple therapy to LABA/LAMA combination.

\section{Strengths and Limitations}

To our knowledge, this is the first study providing experts' opinion on the use of the FDC triple therapy for the treatment of COPD. This study has been carried out using a solid, wellknown and rigorous methodology based on the Delphi technique. $^{21}$ This methodology has permitted the exchange of knowledge and opinion and the reaching of a consensus when there is uncertainty or limited evidence, and when there is not a uniform approach in clinical practice. However, our study also has some limitations: the Delphi technique only provides qualitative results, resulting from the punctuation on the degree of agreement of the panelists, based on the evidence, their clinical practice and experience. These recommendations must be taken as experts' opinion, acknowledging that the sample of panelists is not representative of the whole specialist population. Finally, panelists were all pulmonologists showing their opinions and practice in specialized respiratory units. It is possible that a panel composed of primary care physicians could have given other results that have not been explored with the present design.

\section{Conclusions}

This study provides insights on the use of the FDC triple therapy regarding its efficacy, safety, treatment, devices, and costs, based on the consensus of a 45-expert panel. The results of this Delphi consensus are in general in agreement with international guidelines both in the indication of triple therapy and in that its use in a single inhaler is safe, and is at least as effective with potential additional benefits improving adherence, inhaler management, and cost compared to other forms of inhaled therapy for COPD. The results show that there is a general perception of the benefits of FDC triple therapy over the double therapy LABA/ICS regarding efficacy in improving dyspnea, pulmonary function, quality of life and reducing exacerbations. The effects are perceived to be higher against ICS/LAB than LABA/LAMA therapy. Likewise, safety is perceived to be quite similar among the different options. The divergence found among panelists reveals the complexity of COPD and the need for further scientific evidence to help them to better position the FDC combination in relation to its efficacy, safety and its use in COPD patients. In addition, the discrepancies also reveal that high risk COPD are a heterogeneous and complex group, and the choice of the best treatment depends on many variables that were not always represented in the statements. It is therefore of great importance to continue working towards personalized medicine in COPD treatment.

\section{Acknowledgments}

The authors would like to thank the 45 experts who participated in the Delphi process to express their degree of agreement with the statements: Adolfo Baloira Villar, Agustín Valido Morales, Alberto Fernández Villar, Ana Boldova Loscertales, Antonia Fuster Gomila, Antonio León Jiménez, Arturo Huerta García, Beatriz Abascal, Carlos Antonio Amado Diago, Carlos Cabrera López, Carmen Calero Acuña, Cristina Represas Represas, Cristóbal Esteban González, Eduardo Márquez Martín, Elsa Naval Sendra, Esther Barreiro, Fernando González Torralba, Francisco Javier Callejas González, Germán Peces-Barba Romero, Inmaculada Alfageme Michavila, Javier De Miguel Díez, Jose Luis Izquierdo Alonso, Jose María Echave-Sustaeta, José María Marín Trigo, Jose Miguel Rodríguez González-Moro, Juan Bautista Galdiz Iturri, Juan José Soler Cataluña, Juan Luis García Rivero, Juan Luis Rodríguez Hermosa, Luis Pérez Llano, Luis Puente, Marc Miravitlles, María Cruz González Villaescusa, Marta Palop Cervera, Miriam Barrecheguren, Myriam Calle Rubio, Patricia García Sidro, Patricia Sobradillo Ecenarro, Pedro Jorge Marcos Rodríguez, Pilar De Lucas Ramos, Rafael Golpe, Ramón Agüero Balbín, Rosa Malo De Molina Ruiz, Sagrario Mayoralas Alises, Salvador Díaz Lobato.

The authors would also like to thank GOC Networking team for their support and collaboration in the development of this document and GlaxoSmithKline for their economic and logistic support for this project.

\section{Author Contributions}

All authors made substantial contributions to conception and design, acquisition of data, or analysis and interpretation of 
data; took part in drafting the article or revising it critically for important intellectual content; gave final approval of the version to be published; and agree to be accountable for all aspects of the work.

\section{Funding}

The study has been funded by GlaxoSmithKline. The funder has had no role in the conception of the study, the execution of the field work, the collection of information, the analysis of the results, the preparation or approval of the final version of the article, or the decision to publish it.

\section{Disclosure}

JLLC reports personal fees and non-financial support from AstraZeneca, grants, personal fees and non-financial support from Boehringer Ingelheim, grants, personal fees and non-financial support from Chiesi, personal fees and nonfinancial support from CSL Behring, grants, personal fees and non-financial support from Esteve, personal fees and non-financial support from Ferrer, grants, personal fees and non-financial support from GebroPharma, grants, personal fees and non-financial support from GlaxoSmithKline, grants, personal fees and non-financial support from Grifols, grants, personal fees and non-financial support from Menarini, grants, personal fees and nonfinancial support from Novartis, grants, personal fees and non-financial support from Rovi, grants, personal fees and non-financial support from Teva, outside the submitted work.

BAN reports grants and personal fees from GSK, grants, personal fees and non-financial support from Novartis AG, personal fees and non-financial support from Boehringer Ingelheim, personal fees and non-financial support from Chiesi, grants, personal fees and non-financial support from Laboratorios Menarini, personal fees from Gebro, personal fees from Astra- Zeneca, personal fees from Laboratorios Rovi, personal fees from Laboratorios Ferrer, outside the submitted work; In addition, Bernardino Alcázar Navarrete has a patent P201730724 licensed.

JARM declares received fees for his collaboration as a speaker and/or consultant in conferences, scientific advisory, research projects and scientific publications promoted by AstraZeneca, Bial, Boehringer Ingelheim, Chiesi, Esteve, Gebro, GlaxoSmithKline, Menarini, Novartis, Pfizer, Rovi y Teva.

BGC reports personal fees from AstraZeneca, grants from Boehringer, grants and personal fees from Novartis, grants and personal fees from Chiesi, personal fees from Rovi, grants from Menarini, personal fees from Esteve, outside the submitted work.

BC declares that the institution he works for has received grants from GSK and Astra Zeneca. Advisory boards: GSK, B.I., Astra Zeneca, Novartis, Pfizer. Pulmonx. Boehringer-Ingelheim CJR reports personal fees from Pfizer and Johnson\&Johnson, outside the submitted work.

CCM declares to have received fees for his collaboration as a speaker and/or consultant in conferences, scientific advisory, research projects and scientific publications promoted by AstraZeneca, Bial, Boehringer Ingelheim, Chiesi, Esteve, Gebro, GlaxoSmithKline, Menarini, Novartis, Rovi y Teva. The authors report no other conflicts of interest in this work.

\section{References}

1. Miravitlles M, Soler-Cataluna JJ, Calle M, et al. Spanish guidelines for management of chronic obstructive pulmonary disease (GesEPOC) 2017. Pharmacological treatment of stable phase. Arch Bronconeumol. 2017;53(6):324-335. doi:10.1016/j.arbres.2017.03.018

2. Global Initiative for Chronic Obstructive Lung Disease. Global strategy for the diagnosis, management and prevention of chronic obstructive pulmonary disease - 2019 Report; 2019. Available from: https://goldcopd.org/wp-content/uploads/2018/11/GOLD-2019-v1.5FINAL-04Nov2018_WMS.pdf. Accessed 2019

3. Vanfleteren L, Fabbri LM, Papi A, Petruzzelli S, Celli B. Triple therapy (ICS/LABA/LAMA) in COPD: time for a reappraisal. Int $J$ Chron Obstruct Pulmon Dis. 2018;13:3971-3981. doi:10.2147/ COPD.S185975

4. Lipson DA, Barnhart F, Brealey N, et al. Once-daily single-inhaler triple versus dual therapy in patients with COPD. $N$ Engl J Med. 2018;378(18):1671-1680. doi:10.1056/NEJMoa1713901

5. Papi A, Vestbo J, Fabbri L, et al. Extrafine inhaled triple therapy versus dual bronchodilator therapy in chronic obstructive pulmonary disease (TRIBUTE): a double-blind, parallel group, randomised controlled trial. Lancet. 2018;391(10125):1076-1084. doi:10.1016/ S0140-6736(18)30206-X

6. Vestbo J, Papi A, Corradi M, et al. Single inhaler extrafine triple therapy versus long-acting muscarinic antagonist therapy for chronic obstructive pulmonary disease (TRINITY): a double-blind, parallel group, randomised controlled trial. Lancet. 2017;389(10082):19191929. doi:10.1016/S0140-6736(17)30188-5

7. de Villiers MR, de Villiers PJ, Kent AP. The Delphi technique in health sciences education research. Med Teach. 2005;27(7):639-643. doi:10.1080/13611260500069947

8. Gaduzo S, McGovern V, Roberts J, Scullion J, Singh D. When to use single-inhaler triple therapy in COPD: a practical approach for primary care health care professionals. Int J Chron Obstruct Pulmon Dis. 2019;14:391-401. doi:10.2147/COPD.S173901

9. Worth H, Buhl R, Criee CP, Kardos P, Lossi NS, Vogelmeier CF. GOLD 2017 treatment pathways in 'real life': an analysis of the DACCORD observational study. Respir Med. 2017;131:77-84. doi:10.1016/j.rmed.2017.08.008

10. Zheng Y, Zhu J, Liu Y, et al. Triple therapy in the management of chronic obstructive pulmonary disease: systematic review and metaanalysis. BMJ. 2018;363. 
11. Lopez-Campos JL, Carrasco-Hernandez L, Quintana-Gallego E, et al. Triple therapy for COPD: a crude analysis from a systematic review of the evidence. Ther Adv Respir Dis. 2019;13:1753466619885522. doi:10.1177/1753466619885522

12. Lipson DA, Barnacle H, Birk R, et al. FULFIL trial: once-daily triple therapy for patients with chronic obstructive pulmonary disease. Am J Respir Crit Care Med. 2017;196(4):438-446. doi:10.1164/ recm.201703-0449OC

13. Singh D, Papi A, Corradi M, et al. Single inhaler triple therapy versus inhaled corticosteroid plus long-acting beta2-agonist therapy for chronic obstructive pulmonary disease (TRILOGY): a double-blind, parallel group, randomised controlled trial. Lancet. 2016;388 (10048):963-973. doi:10.1016/S0140-6736(16)31354-X

14. Ferguson GT, Rabe KF, Martinez FJ, et al. Triple therapy with budesonide/glycopyrrolate/formoterol fumarate with co-suspension delivery technology versus dual therapies in chronic obstructive pulmonary disease (KRONOS): a double-blind, parallel-group, multicentre, Phase 3 randomised controlled trial. Lancet Respir Med. 2018;6(10):747-758. doi:10.1016/S2213-2600(18)30327-8

15. Bremner PR, Birk R, Brealey N, Ismaila AS, Zhu CQ, Lipson DA. Single-inhaler fluticasone furoate/umeclidinium/vilanterol versus fluticasone furoate/vilanterol plus umeclidinium using two inhalers for chronic obstructive pulmonary disease: a randomized non-inferiority study. Respir Res. 2018;19(1). doi:10.1186/s12931-018-0724-0
16. Garcia-Rio F, Soler-Cataluna JJ, Alcazar B, Viejo JL, Miravitlles M. Requirements, strengths and weaknesses of inhaler devices for COPD patients from the expert prescribers' point of view: results of the EPOCA Delphi consensus. COPD. 2017;14(6):573-580. doi:10. 1080/15412555.2017.1365120

17. Malerba M, Nardin M, Santini G, Mores N, Radaeli A, Montuschi P. Single-inhaler triple therapy utilizing the once-daily combination of fluticasone furoate, umeclidinium and vilanterol in the management of COPD: the current evidence base and future prospects. Ther Adv Respir Dis. 2018;12:1753466618760779. doi:10.1177/1753466618760779

18. Singh D, Corradi M, Spinola M, et al. Triple therapy in COPD: new evidence with the extrafine fixed combination of beclomethasone dipropionate, formoterol fumarate, and glycopyrronium bromide. Int J Chron Obstruct Pulmon Dis. 2017;12:2917-2928. doi:10.2147/COPD.S146822

19. Lal C, Strange C. Spotlight on fluticasone furoate/umeclidinium/ vilanterol in COPD: design, development, and potential place in therapy. Int J Chron Obstruct Pulmon Dis. 2017;12:135-140. doi:10.2147/COPD.S114273

20. Ismaila AS, Birk R, Shah D, et al. Once-daily triple therapy in patients with advanced COPD: healthcare resource utilization data and associated costs from the FULFIL trial. Adv Ther. 2017;34 (9):2163-2172. doi:10.1007/s12325-017-0604-x

21. Jones J, Hunter D. Consensus methods for medical and health services research. BMJ. 1995;311(7001):376-380. doi:10.1136/bmj.311.7001.376

\section{Publish your work in this journal}

The International Journal of COPD is an international, peer-reviewed journal of therapeutics and pharmacology focusing on concise rapid reporting of clinical studies and reviews in COPD. Special focus is given to the pathophysiological processes underlying the disease, intervention programs, patient focused education, and self management protocols. This journal is indexed on PubMed Central, MedLine and CAS. The manuscript management system is completely online and includes a very quick and fair peer-review system, which is all easy to use. Visit http://www.dovepress.com/testimonials.php to read real quotes from published authors. 